\title{
Epistemological solipsism as a route to external world skepticism
}

\author{
Grace Helton
}

Email: ghelton@princeton.edu

\section{KEYWOR D S}

solipsism, skepticism, social ontology, Turing machine, sentience, external world skepticism, simulation hypothesis, faux-folk, meta-epistemology

There are almost 8 billion human beings on the planet. Some of these I know personally. They are my colleagues, neighbors, friends, and family members. Others are distant strangers, most of whom I will never meet. I take it for granted that all of these beings are, like myself, sentient. I presume that they have opinions and aspirations, hopes and dreads; that they experience intense pleasures and sharp pains, along with dull aches, surprise, simple satisfaction, ennui, and deep longing; that they can reflect, contemplate, learn, interpret the world and themselves, and act on those interpretations. Certainly, I do not think my fellow humans are mere automata, mindless entities that somehow manage to give off the appearance of sentience. In fact, psychologically speaking, it is extraordinarily difficult for me to take seriously, even as a remote possibility, that these others might somehow fail to be sentient. Still, I can ask: Do I know that these others are sentient? Do I know that I am not alone in the universe? ${ }^{1}$

Epistemological solipsism (sometimes abbreviated to solipsism) is the view that I do not know that other minds exist. One way of motivating this view draws from the possibility that others might appear to be sentient whilst altogether lacking a mental life. On one line of reasoning, if I cannot rule out that this possibility obtains, then I do not know that other minds exist, even if the others around me are in fact sentient. ${ }^{2}$

Epistemological solipsism does not enjoy a central place in contemporary philosophical theorizing. ${ }^{3}$ The reasons for this are no doubt complex, but I would conjecture that the following is one contributing factor: epistemological solipsism is presumed to be easily refutable, for instance, on broadly abductive grounds. For presumably the best explanation of why others seem to be sentient is that they are sentient. ${ }^{4}$ If solipsism can be ruled out this easily, then perhaps solipsism doesn't warrant a central position in philosophical theorizing.

I would conjecture than an additional factor which contributes to solipsism's neglected status is the fact that solipsism is sometimes taken to be merely a special instance of external world skepticism. External world skepticism is, at a minimum, the view that vast swathes of your empirical beliefs about the world outside your mind fail to amount to knowledge. Unlike solipsism, external world skepticism enjoys a highly central place in contemporary epistemology; indeed, its refutation is sometimes taken to be the raison d'être of epistemological theorizing. ${ }^{5}$ If solipsism's 
interest consisted merely in the fact that it is a special instance of a far more general and pressing view, then perhaps solipsism's relatively neglected status in the contemporary literature would be justified.

In this paper, I have two broad aims. The first is to show that even if solipsism is in fact refutable, it is at least not obvious what form its refutation might take. For, the most initially attractive routes of rejecting solipsism encounter serious difficulties. My aim is not to show that these difficulties are in principle insuperable; it is the more modest one of showing that it is not a straightforward matter to see how these difficulties might be overcome, with the result that solipsism cannot be dismissed out of hand.

My second and central aim is to show that, for creatures like ourselves, epistemological solipsism is a genuine form of external world skepticism. This is not merely the descriptive point that solipsism, properly understood, falls within the purview of what contemporary epistemologists would count as as external world skepticism. It is also, and more importantly, the normative point that solipsism threatens sufficiently vast swathes of worldly knowledge that it is at least as epistemologically pressing as other forms of worldly skepticism, such as skepticism about chairs. It is thus not right to say that solipsism is merely a special instance of skepticism; for creatures like ourselves, solipsism just is a variety of external world skepticism.

My argument draws in part on the claim that contemporary epistemologists do-and, as a theoretical matter, should - take external world skepticism to be the view that vast swathes of worldly knowledge across multiple domains are compromised, whether or not all worldly knowledge is compromised. Put otherwise, the term 'external world skepticism' should not be reserved for maximally radical variants of the view. I will also show that if knowledge of other minds is compromised, then we lose a surprisingly varied and vast range of empirical knowledge, including at least some knowledge about:

- interpersonal relations

- political affairs

- religious practices

- artistic movements

- social structures and social relations, and

- cultural traditions.

If epistemological solipsism constitutes a genuine form of external world skepticism, then we can draw out some additional morals, namely: No wholly adequate solution to external world skepticism can succeed which does not also solve the problem of epistemological solipsism. And, more tentatively: in assessing proposed solutions to external world skepticism, epistemologists should explicitly consider whether those solutions extend to social knowledge. For even if such proposals do in fact extend to social knowledge, without such a test of adequacy, it is not clear whether we would be justified in endorsing such proposals. Finally, if both of the paper's theses hold-if solipsism is both more resilient than we might have initially thought and is also itself a form of external world skepticism - then perhaps solipsism merits more philosophical consideration than it currently enjoys.

Here is how the paper is structured: After making some ground-clearing remarks ( 1 ), I present one argument for solipsism and show that the most initially attractive responses to this argument encounter initial difficulties (\$2). I then develop and defend the argument that, for creatures like ourselves, solipsism is a form of external world skepticism. The relevant form of skepticism is not 
a maximally radical variant, but it is, I will argue, nevertheless a view worthy of the name 'external world skepticism' (§3). I conclude by reflecting on what morals we should draw for epistemological theorizing $(\$ 4)$.

\section{1 | CLARIFYING THE PAPER'S AIMS}

Before proceeding to the first section, I wish to clarify the paper's aims. The primary claim I will defend is this:

\section{SOLIPSISM-TO-SKEPTICISM}

If I do not know, for seemingly sentient others, whether they are in fact sentient, then a form of external world skepticism is true of me.

This thesis holds of contingency, not of necessity; the argument I will mount in favor of the thesis rests in part on claims about certain contingent and variable-albeit common-aspects of human psychology. For instance, I rely in part on the claim that vast swathes of a statistically typical adult human's beliefs are about or depend on other minds. Some humans might have very few such beliefs. For such people, the fact that they do not know that other minds exist might not compromise vast swathes of their worldly knowledge, and the thesis will not hold of them. Likewise, the thesis might not hold of non-human knowers, such as artificially intelligent beings or extraterrestrial life, should these knowers turn out to have no or few beliefs which are about or dependent on other minds.

The fact that the paper's thesis holds merely of contingency should not diminish its interest. For, on the presumption that we are all even remotely typical humans, this thesis holds of $u s$. That is, the thesis says that if we lack knowledge of other minds, then we will also lose vast swathes of our worldly knowledge, with the result that we fall prey to a kind of external world skepticism.

At this point, one might balk at the suggestion that whether external world skepticism obtains is a function of the contingent traits of some relevant knower. For, it might seem that the term 'external world skepticism' should be reserved for a form of radical skepticism on which none of one's worldly beliefs amount to knowledge, regardless of the content of those beliefs. If this view is right, then whether skepticism holds does not depend on which particular cache of worldly knowledge some subject lays claim to. ${ }^{6}$ All such knowledge, whatever its contents might be, will be compromised. In $\S 3.3$, I argue on both descriptive and normative grounds against reserving 'skepticism' for radical forms of skepticism.

Before proceeding to the main argument, I wish to say something about pluralism about skepticism, the extremely plausible view on which there is not one uniquely valuable way of construing external world skepticism. In arguing that solipsism qualifies as a form of skepticism, I will spend some time considering how skepticism ought be construed, and one might worry that in doing so, I commit myself to the implausible view that there is one uniquely best way to construe external world skepticism.

In fact, I am amenable to pluralism about skepticism and take the contributions of the paper to be consistent with it or at least, to be such that they can easily be made to be consistent with it. Understood in a pluralist light, my thesis is that solipsism entails one (of potentially many) theoretically valuable way of construing external world skepticism. In the paper, I sometimes make claims concerning what is the proper construal of external world skepticism, but for those with 
pluralist leanings, these claims can be harmlessly re-cast as claims concerning $a$ proper construal of skepticism.

I turn next to arguing that solipsism is not easily refuted.

\section{2 | MOTIVATING SOLIPSISM: THE 'LONELY BEING' SCENARIO}

The primary aim of this paper is to show that epistemological solipsism entails-and indeed, for creatures like ourselves, constitutes - a genuine form of external world skepticism. It is no part of my aim to defend solipsism. Still, if solipsism should turn out to be not just refutable but very easily refuted, then this paper's primary claim would likely be of limited interest.

In this section, I argue that solipsism is not easily refuted, whether or not it is refutable. To motivate the thought that solipsism is not easy ruled out, I will develop a particular argument for solipsism and argue that the most initially appealing strategies of rebutting this argument encounter serious difficulties.

There are many ways of arguing for epistemological solipsism. ${ }^{7}$ The particular version of the argument for solipsism I will develop draws in part on the following thought experiment:

\section{'LONELY BEING' SCENARIO}

You are a normally embodied biological being, with hands, legs, and a mouth, eyes and hair. The environment you inhabit is also 'normal,' in that it is physically, chemically, and biologically realized in roughly the way you think it is.

You seem to have friends, family, colleagues, co-nationals, and neighbors. Maybe you think you have a partner or children. It seems to you that there are innumerable non-human animals populating the planet, many of which you presume to be conscious. It seems to you that, all told, there are about eight billion other humans on the planet, though you will never personally interact with the vast majority of these. And, it seems to you that these others are embodied in the same way you are, that is, biologically. These others seem to you to have thoughts, feelings, perceptual states, opinions, aspirations, pains and pleasures, just as you do. It would be psychologically very difficult for you to take seriously the possibility that they lack these states.

In fact, these others in your environment are not biological beings. They are elaborate "multi-modal holograms" of a sort, designed by super-intelligent post-human AI to create perfectly convincing illusions along all relevant perceptual dimensions: visual, auditory, tactile, and olfactory. The effect of these illusions is to simulate in a perfectly convincing way the presence of sentient others. Perhaps post-human AI implemented these multi-modal holograms in order to understand how you, the last of your species, would interact in a more naturalistic social environment. Perhaps these multi-modal holograms are implemented purely by projective technologies. Perhaps they are implemented partly or wholly via neural re-wirings of your own brain. ${ }^{8}$ Whatever the mechanics, these multi-modal holograms are implemented in such a way so as to preclude their sentience. That is, whatever is required for sentience-whether apt functional roles, phenomenal qualities, or something else 
altogether-these multi-modal holograms lack it, due to idiosyncracies of their implementation (and not due to the fact that they are synthetically realized). To say that these 'others' are not sentient is not merely to say that they lack consciousness. They lack any mentality complex enough to be called a psychology. They no more burn with desire than do toasters; no more have points of view than do books on a shelf; no more control their actions than do pixelated figures on a screen. They are what I will call faux-folk.

In one version of the 'lonely being' scenario, the post-human AI who created the projected beings are themselves still around, so you are not alone in the universe. On the assumption that these post-human AI never interact with you, this case is one in which metaphysical nearsolipsism obtains. It is a scenario in which the vast majority of seemingly sentient creatures are not in fact sentient.

In another version of the 'lonely being' scenario, the post-human AI who created you have, for whatever reason, gone extinct. This version of the scenario is a metaphysically solipsistic one, for it is one in which you are the only sentient creature in the universe. In what follows, I will sometimes slide between near-solipsistic and solipsistic versions of the scenario. The considerations I will adduce in favor of the claim that solipsism leads to a form of external world skepticism also support the claim that near-solipsism leads to a form of external world skepticism, so both views are pertinent to the paper's main thesis.

Note that if the 'lonely being' scenario is a solipsistic one, then the others in the universe do not merely lack consciousness. That is, it is not merely the case that it is 'nothing it is like' to be these beings. Rather, these beings lack sentience, where sentience requires, at a minimum, the possession of some suite of suitably integrated and sufficiently diverse mental states and processes. In a word, sentient creatures have inner lives. Because the 'others' in the scenario lack psychologies, they are not zombies, where zombies are physical-functional duplicates of conscious beings which themselves lack consciousness. For, zombies are widely thought to have beliefs, desires, and a whole host of other sophisticated mental states, even though they lack consciousness. ${ }^{9}$ Rather, the seemingly sentient others in the scenario are what I will call faux-folk, where some entity is a member of the faux-folk just in case it lacks sentience. Like toasters, books, and the iPhone's talking assistant, "Siri," faux-folk lack mental lives.

It is worth taking a moment to more fully disentangle the differences between zombies and faux-folk, since this difference will become important later on. I have already mentioned that it is widely presumed that zombies have a suite of sophisticated and diverse mental states and processes; these states and processes are simply never conscious. On this view, zombies are sentient. So, no zombies are faux-folk. Moreover, while zombies are, by definition, physicalfunctional duplicates of sentient beings, faux-folk needn't be physical-functional duplicates of sentient beings. In fact, on most plausible views of the relation between physical-functional traits and sentience, it is necessarily the case that faux-folk are not physical-functional duplicates of sentient beings; for if they were, they would be sentient. If this is right, no faux-folk are zombies. Putting these views together, we have the result that no zombies are faux-folk, and no faux-folk are zombies. The kinds are mutually exclusive.

These clarifications in hand, consider how one might argue for epistemological solipsism by appealing to the 'lonely being' scenario. I will briefly sketch the argument before defending the premises against salient objections. 


\section{THE 'LONELY BEING' ARGUMENT FOR SOLIPSISM}

Premise 1. If you don't know that you're not in the 'lonely being' scenario, then you don't know that other minds exist.

Premise 2. You don't know that you're not in the 'lonely being' scenario.

Conclusion. You don't know that other minds exist.

The first premise can be derived from more general closure principles, such as this one:

\section{KNOWLEDGE IS CLOSED UNDER KNOWN ENTAILMENT}

Suppose $p$ and $q$ are both empirical claims.

If:

(i) S knows $p$, and

(ii) $S$ knows that $p$ entails $q$,

\section{then: S knows $q$.}

According to this principle, if you know that other minds exist, then you know that you are not in the 'lonely being' scenario, since it is knowable that the 'lonely being' scenario is inconsistent with your knowing that other minds exist.

To say that closure principles have been much discussed in the literature would amount to the driest of understatement. ${ }^{10}$ Instead of weighing in on this long-standing and fraught dispute, I will present some of the points commonly made in favor of closure principles. I will take it as a given that there is much that can and has been said against these considerations.

One putative virtue of the closure principle is that it captures intuitions about ordinary cases of empirical knowledge. For instance, suppose you know you parked on Morris Street and that this fact is inconsistent with your having parked on Witherspoon Street. If someone were to ask you "How do you know you didn't park on Witherspoon Street?" a natural and cogent reply would be "Because I know I parked on Morris Street." It seems that you can know that you didn't park on Witherspoon in virtue of knowing that some other relevant state of affairs obtains which is inconsistent with your parking on Witherspoon. This phenomenon seems to generalize. For instance, it seems that you can know that you didn't order the tofu by knowing that you only ordered the steak; that you can know that a dress isn't green by knowing that it is red all over; and that you can know that the coffee hasn't run out by knowing that there is some coffee left.

Another classical motivation for accepting some form of closure principle is that to reject closure is to endorse some highly counter-intuitive claims, sometimes called "abominable conjunctions." For to reject the closure principle would be to claim that it is possible that you might: know that you only ordered steak and yet fail to know that you didn't order tofu; or that you might know that your dress is red all over without knowing it isn't green; or that you might know the coffee hasn't run out and yet not know that there is coffee left. These possibilities are not incoherent, but they are difficult to accept. ${ }^{11}$ Better, some have thought, to embrace closure than to countenance such possibilities.

The second premise says that you don't know that you're not in the 'lonely being' scenario. On the face of it, this premise might seem the argument's obvious weak link, since it might seem that you might easily know this. For one thing, it's not obvious that faux-folk are even possible. For, on one metaphysics of sentience, behaviorism, any entity which possesses relevant behavioral 
dispositions is necessarily sentient. If this view is right, then faux-folk are impossible on conceptual grounds.

For another thing, even if the 'lonely being' scenario is possible, it is wildly implausible, a fanciful story plucked from science fiction, surely not a possibility we need to take seriously. Even if our experiences of others might be explained by their being elaborate, multi-modal illusions, hologram-like entities designed to deceive us with respect to our visual, tactile, and olfactory senses, surely it is a far better explanation of our evidence that these others are sentient. If this is right, then the 'lonely being' scenario can be easily ruled out on broadly abductive grounds.

I will suggest that none of these objections against the argument is obviously decisive. Again, my aim is not to claim that these objections could not be made to work, appropriately supplemented; it is rather the more modest one of showing that it is not obvious how these initially attractive replies might ultimately succeed.

\section{1 | The 'Lonely Being' Scenario and the Metaphysics of Sentience}

First, consider the objection that the 'lonely being' scenario is impossible, for the reason that behaviorism holds; any entity which has the behavioral dispositions of a sentient being is in fact sentient. If behaviorism is true, the 'lonely being' scenario is impossible; the hologram-beings would have to be themselves sentient. But, there are much-discussed reasons for thinking that behaviorism is an implausible view. A classical objection stems precisely from the claim that a being who fully simulates sentience-or some aspect of it—isn't necessarily sentient, such as Turing's famous machine who can engage in open-ended conversation just as a human can but who is intuitively not a thinking being. ${ }^{12}$

A more plausible version of this objection would appeal to a special form of functionalism. In general, functionalism is the view that some entity is sentient if its mental states or processes satisfy certain functional roles, where a functional role is exhausted by the following three types of dispositions: world-to-mind dispositions, mind-to-mind dispositions, and mind-to-world dispositions. On the face of it, this form of functionalism does not provide a way to argue that the putative faux-folk of the 'lonely being' scenario are in fact sentient; for these faux-folk have the same third-personally observable profiles of other sentient beings, but they might lack the same functional roles; in particular, they might lack the 'internal' or mentality-involving aspects of the functional roles.

However, there is one special variant of functionalism that might exclude the 'lonely being' scenario. This is one on which sentience is equivalent to some functional role but on which the third-personally observable, wholly 'behavioral' aspects of those functional roles wholly determine the mental ones, such that necessarily, any being with certain world-involving functional roles necessarily also has the mental-involving aspects of the functional roles. ${ }^{13}$

As it turns out, the form of functionalism on which world-involving or 'external' aspects of the roles wholly determine 'internal' or mental-involving aspects of functional roles falls for the very same reason as does behaviorism. Consider, for instance, one particular kind of Turing machine, Ned Block's 'blockhead' program, which is a hypothetical, brute force computer program which manages to provide a cogent answer to every possible question in the human language via answers pre-determined both by that question and by all previous questions in some conversational node. This program is a 'brute force' program in the sense that it is nothing more than an extremely large look-up table. Would such a program necessarily instantiate 'internal' or mental representations, just in virtue of its ability to converse in a seemingly intelligent way? Given this program's internal 
structure, which amounts to little more than a list of possible answers to all possible (finite) questions, it would seem odd to posit that the program enjoyed mental representations. It would be very odd to claim, for instance, that this particular program involves any sensitivity to semantic or even syntactic features of language, its behavioral competence notwithstanding (this isn't of course to suggest that no computer program could evince this sort of sensitivity. It is just to point out that a program with the relevant behavioral competencies needn't have any correlative semantic or syntactic sophistication). ${ }^{14}$ I conclude, then, that we lack a reason to think that behavioral dispositions guarantee correlative mental representations. This is because, for reasons familiar from $20^{\text {th }}$ century philosophy of mind, we should resist the view that behavioral dispositions, no matter how sophisticated, guarantee the presence of mental representations. ${ }^{15}$

\section{2 | The 'Lonely Being' Scenario and the Grounding of the Mental in the Physical}

So far, I've argued that we can't obviously rule out the 'lonely being' scenario by appealing to the metaphysics of sentience. A different view, one which is orthogonal to the question of whether behaviorism, functionalism, or some other view is true, concerns the grounding of the mental in the physical. Many theorists accept that physical duplicates of sentient entities are necessarily themselves sentient. They merely disagree about why brain-duplicates of sentient beings are themselves sentient. Behaviorists will say it's because behavioral dispositions are preserved, functionalists will say it's because the functional role is preserved, phenomenalists will say it's because phenomenal aspects are preserved. I will focus on brain duplicates, but we might also extend the question to embodied duplicates.

If we accept that brain duplicates of sentient creatures must themselves be sentient, then the following dilemma arises: If, on the one hand, the putative faux-folk in the scenario are brainduplicates of sentient creatures (such as yourself), then these putative faux-folk aren't faux-folk at all. They are sentient creatures. They have all the thoughts, feelings, desires, emotions, and feelings of their duplicates. If, on the other hand, the faux-folk are not brain-duplicates of sentient creatures, then there is evidence that you might acquire-at least in principle-that would help you determine that these creatures aren't sentient. For instance, you might throw yourself into the study of neuroscience and conduct a comparative study of your brain and the brains of your peers and in this way acquire empirical evidence of dissimilarities between your brain and theirs. Should you discover no systematic, relevant different between your own brain and theirs, then you have at least some (defeasible) inductive evidence that the scenario does not obtain. If this is right, then even if you don't presently know that you are alone in the universe, you might come to know that you are the only sentient creature.

The way to respond to this dilemma is to embrace its second horn: even if the personsimulations have brains (or, 'brains') that are indistinguishable from yours and even if brainduplicates of sentient beings are necessarily sentient, this would not give you evidence that they have brains that are in fact duplicates of yours. For recall that the faux-folk are multi-modal holograms of a sort, somehow created by projective technologies, neural rewirings of your own brain, or some combination of the two. There is no reason to think that the brains-or rather, 'brains'of faux-folk would reveal anything substantive about the functional roles or mechanisms which explain faux-folk behavior.

I conclude that the widely held view that the mental is somehow grounded in the physical does not give us a way to exclude that the 'lonely being' scenario might be our own. 


\section{3 | Can We Rule Out the 'Lonely Being' Scenario on Abductive Grounds?}

Even if the 'lonely being' scenario is metaphysically possible, we might think that it is extremely improbable, such that we can be said to know, on abductive grounds, that it does not obtain. For surely, the best explanation of why others appear to be sentient is that they are sentient, with the result that the second premise is false; we know we are not in the 'lonely being' scenario.

Perhaps an abductive solution to solipsism might ultimately succeed, but it is far from obvious how it might. To see this, consider that the 'lonely being' scenario is roughly as probable-and perhaps more so-than another scenario which some have taken to be sufficiently probable so as to take seriously as a description of the actual world. I have in mind the simulation hypothesis, according to which we, the world, and everything in it is the simulation of highly powerful post-human AI. ${ }^{16}$ Contemporary interest in the simulation hypothesis is largely due to Bostrom's (2003) influential argument that there are reasons to take the hypothesis seriously. The argument Bostrom develops depends in part on the claim that computers will ultimately approach incredibly fast processing speeds of the kind that would easily permit them to simulate full-scale human civilizations. It also draws on the claim that post-human AI would be interested in simulating these worlds, for instance, for entertainment or research purposes. Bostrom concludes that if we put these claims together, we have some reason to think that a huge number of full-scale simulations of human civilizations will ultimately be created, with the result that it is extremely likely that our own world is one such simulation.

Bostrom's argument has been undeniably influential, gaining a hold not only on other philosophers but also on some physicists, some of whom have developed strategies for testing it. My aim here is not to assess the complex issues raised by the simulation argument. Just a couple of the issues that would have to be addressed include: The likelihood of super-intelligent computers and the likelihood of certain practical and ethical constraints on such super-intelligent computers. Rather, my aim is merely to point out that some of the same considerations which Bostrom adduces in favor of the simulation hypothesis also support something like the 'lonely being' scenario. While Bostrom supposes that the simulation hypothesis is one in which both you and others are sentient, albeit simulated, it's not obvious why this should be the case. Suppose that pre-AI humans solve 'the control problem,' which is the problem of how to ensure that any superintelligent AI would respect the rights of humans. If post-human AI are engineered to respect the rights of humans, it's unclear why they would be willing to simulate billions of sentient creatures, many of whom will foreseeably suffer in extreme and needless ways, at the hands of disease, natural disaster, and other woes not caused by humans. This consideration might suggest that the most probable version of the simulation hypothesis is one in which you are the only sentient creature in the simulation or perhaps one of a few sentient creatures. But, why, if bound by ethical constraints would post-human AI simulate any sentient beings at all, given that those beings might suffer in extreme and needless ways? Perhaps, much like many actual human animal researchers, they would take the aims of their research to justify this creation project for a few humans but not for seven billion. Whether these considerations are ethically correct is entirely beside the point; the question is only whether they are the kinds of considerations post-human AI engineered by humans might take into account.

Thus, there are some reasons to think that the most plausible version of the simulation hypothesis is a solipsistic or near-solipsistic one. What, though, of the 'lonely being' scenario in particular, wherein the world is not simulated, save for the multi-modal holograms which convincingly 
simulate sentient others? The considerations in favor of the claim that ours is this scenario are somewhat different than those in favor of a solipsistic version of the simulation hypothesis, but there is some overlap. Supposing the rise of super-intelligent AI is extremely likely, we might take seriously the suggestion that these AI might have reason to implement multi-modal holograms of the kind present in the scenario, for the reason of studying the last human(s) in her natural social environment. ${ }^{17}$

In light of the preceding considerations, I think we should at least feel uneasy about the prospects of a straightforward abductive argument against solipsism. Perhaps such an argument can ultimately succeed, but a development of this argument would require a substantive engagement with the kinds of scenarios which are rendered far more plausible in light of the view that super-intelligent AI will inevitably emerge, given certain foreseeable expansions of current computer power. I conclude that solipsism cannot be easily dismissed by appealing to abductive considerations, even if these considerations might ultimately succeed.

So far, I've argued that some of the most initially appealing strategies of rejecting the 'lonely being' argument for solipsism encounter difficulties. ${ }^{18}$ Perhaps these difficulties can be overcome, but the path is an encumbered one. Though modest, this conclusion serves my present purpose of defusing a certain anticipated objection to my main thesis, namely that solipsism is so easily excluded so as to render the question of its connection to external world skepticism a wholly uninteresting one.

\section{3 | EPISTEMOLOGICAL SOLIPSISM AS A ROUTE TO EXTERNAL WORLD SKEPTICISM}

Having said something about the resiliency of solipsism, I turn to the argument for my primary claim, which is that, for creatures like ourselves, epistemological solipsism entails external world skepticism. I will defend each premise shortly:

\section{THE SOLIPSISM-TO-SKEPTICISM ARGUMENT}

Premise 1. By stipulation, some belief is a social belief only if: that belief depends for its truth on other minds, and the fact that that belief depends for its truth on other minds is conceptually accessible.

Premise 2. If I do not know that other minds exist, then none of my social beliefs amount to knowledge.

Premise 3. External world skepticism is true of me if vast swathes of my (valuable) worldly beliefs across multiple domains do not amount to knowledge.

Premise 4. My social beliefs comprise vast swathes of my (valuable) worldly beliefs across multiple domains.

Conclusion. If I do not know that other minds exist, then external world skepticism is true of me.

\section{1 | Social Beliefs}

The first premise is a stipulative, partial characterization of what I am calling social belief. On this characterization, if some belief is a social belief, then: (i) that belief depends for its truth on 
other minds and (ii) the fact of that belief's dependence on other minds is conceptually accessible. We might construe the claim that for a belief to 'depend for its truth on other minds' is, roughly, for that claim to be false in any world in which other minds don't exist. This characterization is deliberately neutral on the question of whether the fact of the belief's dependence on other minds must be conceptually accessible for the actual subjects who token such beliefs or merely for their suitably idealized counterparts.

Some might worry that in employing the term 'social beliefs' to describe mind-dependent beliefs, I am making a question-begging presumption about the relation between the social and the mental. While I will ultimately suggest that at least some social facts depend on certain mental facts, this point comes later in the argument, not at this first, terminological step. Those who have this concern about the terminology are free to substitute any other term, such as 'beliefs dependent on other minds' or 'anti-solipsistic beliefs.' Nothing should turn on the term employed.

\section{2 | Closure Again}

Like the argument for solipsism, the argument that solipsism entails a form of skepticism draws on a closure principle, such as the following:

\section{KNOWLEDGE IS CLOSED UNDER KNOWN ENTAILMENT}

Suppose $p$ and $q$ are both empirical claims.

If:

(i) S knows $p$, and

(ii) $S$ knows that $p$ entails $q$,

then: S knows $q$.

If this principle is true, then it follows that if one doesn't know that other minds exist, then none of one's social beliefs count as knowledge. I refer the interested reader to the brief discussion of this principle in $\S 2$.

\section{3 | The 'Vast Swathes' Construal of External World Skepticism}

The third premise is a claim about what external world skepticism amounts to. It is the claim that if vast swathes of our beliefs about the contingent, a posteriori aspects of the world outside our mind do not amount to knowledge, then external world skepticism obtains. (I have already been referring to these beliefs as empirical beliefs or worldly beliefs). Notice that this characterization is silent about what portion of knowledge must be compromised in order for skepticism to obtain, if indeed, speaking of one's portion of knowledge is even coherent. ${ }^{19}$ Call this partial characterization of skepticism the 'vast swathes' construal of skepticism.

THE 'VAST SWATHES' CONSTRUAL OF SKEPTICISM External world skepticism is true of some individual $S$ if vast swathes of $S$ 's beliefs across multiple domains fail to amount to knowledge. 
This view has two salient competitors, namely:

THE RADICAL CONSTRUAL OF SKEPTICISM External world skepticism is true of some individual $S$ only if none of $S$ 's worldly beliefs amount to knowledge.

THE NEAR-RADICAL CONSTRUAL OF SKEPTICISM External world skepticism is true of some individual $S$ only if virtually none of $S$ 's beliefs amount to knowledge.

There are both descriptive and normative reasons for thinking that the 'vast swathes' construal of external world skepticism is to be preferred to both the radical and near-radical variants.

First, to make the descriptive point: Contemporary epistemologists commonly take 'external world skepticism' to mean something like 'vast swathes' skepticism. While 'vast swathes' skepticism is consistent with radical and near-radical variants, 'external world skepticism' is not reserved for either of these forms. To establish this, I focus on the role recent envatment scenarios have played in certain recent debates and in particular, on the nearly universal presumption that were we in such a scenario, external world skepticism would obtain.

Recent envatment scenarios are scenarios in which, despite appearances, we are brains-in-vats and in which our envatment came about very recently, say, five seconds ago. In such worlds, we have spent most of our lives embodied in the usual way, interacting with mind-independent objects, but we have, without our knowledge, recently been forced into an envatted existence.

Epistemologists tend to treat recent envatment scenarios as ones in which our beliefs about the past, including the very recent past, amount to knowledge. At the same time, epistemologists presume that were we recently envatted, our beliefs about events in the present and at least near future would not amount to knowledge. So, beliefs such as I had red hair last year, there were four chairs in here yesterday, or The Normans invaded England in 1066 will count as knowledge in this scenario, but beliefs such as there are three chairs in this room, I have dark hair or Jess is about to make an omelette will fail to amount to knowledge.

The aim here is not to evaluate whether it is correct to classify recent envatment scenarios as skeptical scenarios. Rather, the aim is to use the fact that contemporary epistemologists largely accept this claim as evidence about how epistemologists construe external world skepticism. Clearly, the recent envatment scenario is not one in which all of your worldly knowledge is lost. Much of your knowledge of the past is preserved. It also seems unlikely that the recent envatment scenario is one in which virtually all of your worldly knowledge is lost. For this to be the case, you would have to be an unusually present- and/or forward-looking person, with very few beliefs about the past, even about the quite recent past. Notably, theorists take it to be obvious, to the point of needing no defense whatsoever, that the recent envatment scenario is a skeptical scenario. ${ }^{20}$ This suggests that these theorists take it to be sufficient for some scenario to be a skeptical scenario that it compromises vast swathes of your worldly knowledge across multiple domains. ${ }^{21}$

Suppose, as I have just suggested, that contemporary epistemologists employ 'external world skepticism,' in a way that is consistent with the 'vast swathes' rendering of external world skepticism. It remains a possibility that this practice is a mistaken one. Perhaps in permitting 'skepticism' to pick out non-radical scenarios, epistemologists have misjudged the aims of their own discipline. On this proposal, epistemologists should use 'external world skepticism' to pick out only scenarios in which all or virtually all of a knower's worldly knowledge is compromised.

I think we should reject the suggestion that 'external world skepticism' ought to be reserved for radical and near-radical skepticism, which isn't to say that there are no contexts in which we 
might wish to focus our attention on radical skepticisms. Very roughly, here is why: The reason skepticism is epistemologically interesting is that it is a situation which threatens our selfconception as creatures whose views about important aspects of the world largely amount to knowledge. If this is right, then it makes sense to treat any situation in which many of our worldly beliefs fail to amount to knowledge as a skeptical scenario, even if those beliefs do not comprise all or virtually all of our worldly knowledge. For all of these are scenarios which threaten our status as creatures whose views of the world are mostly accurate and mostly amount to knowledge.

The previous consideration tells against reserving 'external world skepticism' for radical variants, but, insofar as it invokes valuable knowledge, it also speaks in favor of a slight variant of the 'vast swathes' construal of skepticism, as follows:

THE 'VAST SWATHES OF VALUABLE BELIEFS' CONSTRUAL OF SKEPTICISM External world skepticism is true of some individual $S$ only if vast swathes of $S$ 's valuable worldly beliefs, across multiple domains, fail to amount to knowledge.

I take it that the literature on envatment is consistent with the 'vast swathes of valuable beliefs' construal but doesn't uniquely support it. This literature is consistent with this reading because the kinds of knowledge compromised by recent envatment scenarios include much valuable knowledge, such as knowledge of political history and knowledge of one's own past. Here, I briefly defend this construal by reflecting on a view we might call 'junk' skepticism. According to 'junk' skepticism, none of my junk beliefs, where these are beliefs of little or no value, amount to knowledge. ${ }^{22}$ For instance, my belief that there are two commas in the sentence I read a few moments ago is not knowledge. Likewise, my belief that the stop sign by my house is a bit bent at the top or my beliefs about the lyrics to a bad song I don't care about-for whatever reason, none of these amount to knowledge. (We might get to this view by considering the possibility that some bored evil demon has deceived me on exclusively trivial matters).

Many of our beliefs are junk beliefs, in that they have little or no value. So, it is plausible that for most of us, junk skepticism would compromise vast swathes of our knowledge across multiple domains. So, if 'external world skepticism' ought to be construed in the strictly non-normative 'vast swathes' way, then junk belief skepticism is a variant of external world skepticism. To my mind, 'junk' skepticism doesn't warrant the honorific 'external world skepticism.' It is not worthy of the name precisely because 'external world skepticism' is determined by relevant philosophical aims, and it is unclear what the value is in defusing a view such as 'junk' skepticism. If this is right, then it is false that if vast swathes of our beliefs across multiple domains amount to knowledge, then skepticism obtains. These beliefs must additionally be of value.

Going forward, I will presume that we ought to construe skepticism in the 'vast swathes of valuable beliefs' way. But note that the present point I make about solipsism constituting a form of skepticism would follow whether or not we accept this construal of skepticism or its nonnormative, 'vast swathes of beliefs' counterpart. Moreover, even if we reject a normative construal of skepticism, it seems significant that solipsism threatens our most valuable beliefs. Indeed, the points of the next section should make vivid that solipsism is at least potentially a more significant form of skepticism than other variants of worldly skepticism, insofar as solipsism threatens what are, at least potentially, our most important varieties of knowledge. To put the point otherwise, even some of those who cannot be bothered to fret too much about skepticism about (say) whether trains exist will be-and should be-deeply disturbed by the prospect that we don't know whether those around us have inner lives. ${ }^{23}$ 


\section{4 | Social Beliefs Comprise Vast Swathes of External World Knowledge}

The argument's fourth premise is the claim that social beliefs-i.e., beliefs whose truth depends on the existence of other minds-comprise vast swathes of what we think we know about the world. Moreover, social beliefs cross multiple intuitively distinct domains of knowledge, including politics, history, culture, and religion.

Let's suppose that metaphysical solipsism holds; you are, contrary to appearance, the only sentient creature in the universe. The seemingly sentient creatures around you are mere automata, faux-folk. In this situation, which of your beliefs would turn out to be false? I will argue that all or many of the beliefs in each of the following categories will turn out to be false in this world:

- Beliefs which attribute mentality or specific mental states to others

- Beliefs which attribute actions to others

- Beliefs which posit or presuppose social entities.

In suggesting that solipsism would render all or many of your beliefs in each of these categories false, I do not mean to suggest that these are the only kinds of beliefs which solipsism would render false. My aim is not to provide an exhaustive list of such beliefs but rather to provide reason to think that sufficiently many of your beliefs would be false so as to trigger external world skepticism.

First, and most straightforwardly, consider those of your beliefs which attribute mental states to others. In the 'lonely being' scenario, your beliefs attributing desires, perceptual states, twinges, tickles, views, ideas, intentions, wishes, feelings, or other mental states to others will be false because all of these 'others' are faux-folk; they seem sentient, but aren't. For instance, consider a prosaic encounter with your friend ('friend'?) Marie at the local grocery store. In greeting you, Marie smiles warmly and gives your arm a friendly touch. You ask her how she has been. She mentions that the day before, she went to the park with some friends, and they really enjoyed playing Frisbee. She also mentions that she's worried about some problems her niece has been having with the other kids at school. This encounter will likely result in your having beliefs such as the following (among many others):

(1) Marie is happy to see me.

(2) Marie and her friends enjoyed playing Frisbee.

(3) Marie is worried about some problems her niece has been having with other kids at school.

Since Marie is a member of the faux-folk, none of these beliefs are true. Your belief that Marie is happy to see you is false because Marie has no feelings whatsoever, so she certainly doesn't have any to spare on you. Likewise, your belief that Marie and her friends had a great time playing Frisbee is false because having fun involves pleasure which neither Marie nor her friends will have had, lacking the very capacity for it. (It also seems rather doubtful that Marie might count as having friends, given her-and their-non-sentience, but I'll leave that question to one side). Of course, the points about (1)-(3) extend to any of your beliefs which attribute particular mental states-desires, thoughts, wishes, urges, perceptual states, moods-to members of the faux-folk. Presumably, such beliefs will occupy a large piece of real estate in your mental life. As extremely social creatures, we think about others very often-in passing, as when we glimpse a stranger's 
scrunched face and register their worry; in some depth, as when we converse with someone; obsessively, as when we dissect the most recent interaction with our love interest, trying to decipher their feelings; or contemplatively, as when we reflect on the value or nature of a particular, deeply important relationship, such as a relationship with a very good friend, a partner, or a deceased parent. So just in virtue of straightforward beliefs about the psychology of those you interact with, the 'lonely being' scenario compromises vast swathes of your worldly beliefs.

Furthermore, it is not only beliefs about individuals known to you to whom you will attribute mentality. Many beliefs about politics, aesthetic movements, and historical figures attribute particular mental states to others or to groups, and at least some of these will be false. For instance:

(4) Many mannerists wanted to depart from Renaissance ideals of form and balance.

(5) Some Buddhists don't believe in the self.

(6) Commentators were surprised by the Brexit vote.

(7) Most who join online dating sites hope to meet a romantic partner.

(8) Kim Jong-un anticipated a response from South Korea.

(9) Some Amish teenagers feel anxiety when trying to decide whether to commit to their parents' lifestyle.

(10) She is trying to make pancakes. ${ }^{24}$

I suspect that if only beliefs about the mental states of others were false, solipsism would likely constitute a form of skepticism; we need only reflect on how varied and many these beliefs are to have some reason to think that solipsism would compromise vast swathes of beliefs across many domains. But, it is not only beliefs that explicitly attribute particular mental states to others that will turn out false in the 'lonely being' scenario. Consider next beliefs which attribute actions to others. At least many of these beliefs will be false, for the reason that at least many actions are partly constituted by certain proximal intentions, such that someone cannot count as performing that action if they lack the relevant proximal intention.

For instance, consider the action of fleeing. It is not enough to flee someone that you self-propel away from them. Suppose you are jogging and, unbeknownst to you, a curious squirrel scampers after you. You do not flee this squirrel, even though you do self-propel away from it. This suggests that some additional condition is required for fleeing. I propose that what is needed is a proximal intention of evasion. You do not flee the squirrel because you don't intend to evade it, you just happen to self-propel away from it.

Importantly, to say that fleeing is partly made up of a proximal intention of evasion is not to claim that fleeing involves a distal intention of evasion. One's more ultimate intention in fleeing might in fact be to get caught. For instance, my six-year-old nephew might flee me because he wants to get caught and tickled by me. His ultimate or distal intention is to get caught, not to evade me. Nevertheless, in fleeing from me, he acts on a more proximal intention of evasion, which is what makes his action one of fleeing and not merely one of self-propulsion away from me. ${ }^{25}$

What goes for fleeing also goes for a wide range of other actions: protesting, creating, interpreting, navigating, constructing, memorializing, performing-these are all proximal intentionsinvolving actions. If one lacks the relevant proximal intentions, one cannot count as carrying out these actions.

Consider, for instance, the action of protesting. Suppose someone without any political leanings is asked to hold a sign for someone else, utterly unaware that on one side the sign advertises a political slogan criticizing some political policy. Suppose further that this sign holder has no 
opinion about the relevant policy, indeed, is completely ignorant of its existence. This person is doing many things; she is holding a sign, and the sign might, quite unbeknownst to her, have a certain meaning and even a certain amount of political efficacy. But, she is not protesting. Similar points apply mutatis mutandis to a whole slew of other actions; they necessarily involve relevant proximal intentions.

If many actions are partly made up of proximal intentions, then in the solipsistic scenario, any beliefs which attribute such actions to others will be false. And you are likely to have many such beliefs. Some of these involve individuals known to you. Many involve political, historical, or cultural events. I submit that these are examples:

(11) Hundreds of thousands of Syrians fled the violence in their homeland.

(12) My friend will design a birthday cake for me.

(13) Dolly Parton pioneered a new approach to country, one which drew on both singer-songwriter and Gospel traditions.

(14) Those people are chasing a bus.

(15) That philosopher is carefully analyzing those arguments.

Given that these actions involve proximal intentions, all of (11)-(15) will be false. Of course, some beliefs in the vicinity of (11)-(15) will be true. For instance, suppose that you see a member of the faux-folk rapidly moving in the direction of a bus which has just departed. He looks to you to be chasing the bus. ${ }^{26}$ Given that chasing involves a proximal intention of catching up to someone or something else, this member of the faux-folk isn't chasing the bus. However, he is moving after the bus. For moving is not an activity which requires sentience. Boulders can move, as when they roll down steep slopes. Leaves can move, as when they flutter in the breeze. So, the claim that in the solipsistic scenario, (14) is false, is not to claim that there is no belief in the vicinity that is true. But it is to claim that a belief of a kind that you are very likely to have, and moreover, a belief that is crucial to your understanding of others, is false.

So far, I have argued that beliefs which attribute mental states to others will be false, as will many beliefs which attribute certain actions to others. I suspect that if solipsism compromises just these two forms of knowledge, solipsism will compromise sufficiently vast swathes of our worldly knowledge so as to trigger a form of external world skepticism. However, I will attempt to bolster this claim by arguing for an additional, more controversial claim, namely that if solipsism is true, at least many beliefs which posit or presuppose social entities will turn out to be false.

Social entities include countries, cities, regulatory bodies, judicial courts, branches of government, schools, businesses, and social clubs. On one view, such entities are partly comprised of certain persons' or group's consent or recognition. Consent and recognition in turn plausibly require mental states - such as assent, belief, perhaps the capacity for action-of the kind faux-folk cannot confer. On this psychological approach to social ontology, beliefs like the following will be false:

(16) The Knesset is a legislative assembly.

(17) My friend is part of the Catholic Church.

(18) Botswana is a country. ${ }^{27}$

Of course, there is a competing approach to social ontology, one on which beliefs like those expressed in (16)-(18) do not depend on the consent or recognition of others. This is the structuralist approach, on which social entities are determined by purely behavioral considerations, not by 
mental states. On this view, what it is to be (say) a country club is to be treated like a country club by relevant others, regardless of the attitudes of those others. Likewise, countries, associations, money, borders, and other social entities exist wholly in virtue of behavioral dispositions, regardless of whether those dispositions are further grounded in attitudes like assent, recognition, or belief. $^{28}$

Needless to say, it is outside the scope of this paper to adjudicate between psychological and structuralist approaches to social ontology. At the same time, it is worth noting that there are forms of the structuralist approach according to which (16)-(18) will be false in the 'lonely being' scenario. These are forms of structuralism on which social entities are partly comprised of the relevant behavior of sentient entities. On such views, social entities are wholly comprised of purely behavioral dispositions and not the attitudes, if any, which ground those dispositions, but only those who have some psychology or other-that is, those who are sentient-are such that their behavior can contribute in this way to the existence of social entities. On such a view, the behavior of a sophisticated non-sentient machine, even if behaviorally like that of a sentient creature, cannot help ground social entities. On this variant of structuralism, the behavior of the fauxfolk can't help create countries, clubs, borders, and the like, because faux-folk aren't sentient and therefore-like toasters, avocadoes, and molecules - their behavior is simply irrelevant to the existence of social entities. ${ }^{29}$

I take it, then, that for typical humans, vast swathes of knowledge are compromised by the 'lonely being' scenario. The forms of knowledge compromised by this scenario are not only vast, they cross many intuitively distinct domains of knowledge, including, of course, knowledge about the mental states of those with whom we interact but extending also to at least some forms of knowledge about religion, culture, policy, and the actions of individuals and groups andpotentially- the very existence of some social entities and processes. ${ }^{30}$ These beliefs, or at least very many of them, are valuable beliefs, indeed, some of them are among the most valuable beliefs we have, including beliefs about who we love and are loved by, beliefs about our commonality with other humans, and more abstract beliefs about the social fabric of our world. If, as I have argued, external world skepticism should be construed as the view on which vast swathes of our valuable knowledge across multiple domains is compromised, we have good if defeasible evidence that, for creatures like ourselves, epistemological solipsism entails a genuine form of external world skepticism.

At this point, a critic might grant that solipsism compromises vast swathes of knowledge across many domains. Indeed, she might even grant that the considerations I have adduced suggest that the range of knowledge compromised by solipsism is vaster and crosses more domains than she might previously have appreciated. Still, she might maintain that we have been given no reason to think that for creatures like ourselves, solipsism entails a form of skepticism. For, she might doubt whether the range of knowledge compromised by solipsism is sufficiently vast so as to render solipsism a form of skepticism or whether the domains of knowledge compromised by solipsism are sufficiently many so as to render solipsism a form of skepticism. ${ }^{31}$

I take the point that the 'vast swathes of valuable beliefs' construal skepticism is too schematic to permit anything like a deductive entailment between a putative form of skepticism and a conclusion about whether, according to this construal, that form qualifies as a form of skepticism. Still, I would suggest that the reasons I have adduced constitute good if defeasible reason to think that solipsism entails a form of skepticism.

The way for my opponent to defeat these reasons would be to articulate and defend a more precise construal of skepticism, one on which the following desiderata are both met: It must predict that solipsism is not a form of external world skepticism, and it must predict that the form of 
skepticism suggested by recent envatment scenarios, namely skepticism about the present/nearfuture, is a form of skepticism. (See $\$ 3.3$ for a defense of this thought.) That is to say, the relevant construal must predict both that the kinds of knowledge compromised by skepticism about the present/near-future are sufficiently vast and sufficiently domain cross-cutting so as to qualify this form of skepticism as a variant of external world skepticism and that the kinds of knowledge compromised by solipsism are insufficiently vast or insufficiently domain cross-cutting so as to qualify solipsism as a form of external world skepticism.

I must confess that I find it difficult to imagine a plausible defense of a construal of skepticism which satisfies both of the aforementioned desiderata. For one thing, it is not obvious whether, for typical humans, beliefs about the present and/or near-future tend to outstrip beliefs that are about or dependent on other minds; if they don't, it's not clear that it will be possible for a construal to leave solipsism outside of the class of skepticism and skepticism about the present/near-future within it. For another thing, the defense of this view must be made on grounds other than the ad hoc one that it would permit us to avoid the conclusion that solipsism is a form of external world skepticism. Offhand, it is difficult to see what form that motivation might take. But, rather than arguing from the limits of my own imagination, I will leave the reader with this claim: The critic who wishes to take up this challenge shoulders a heavy burden. ${ }^{32}$

\section{4 | WHAT MORALS SHOULD WE DRAW?}

I have suggested that epistemological solipsism is more resilient than we might have thought. I have also suggested that solipsism is, for creatures like ourselves, a form of external world skepticism. What follows from these claims? If, as previously conjectured, philosophers' relative neglect of solipsism is partly due to the presumption that solipsism is merely an easily refuted special instance of a more pressing view, then these results should perhaps inspire epistemologists to give solipsism more philosophical attention than it currently enjoys.

Far more tentatively, I would suggest that if solipsism is, for creatures like ourselves, a form of external world skepticism, a moral about method in epistemology follows, namely: Proposed solutions to external world skepticism should be assessed with a special eye to whether those putative solutions extend to knowledge of other minds. For if they do not, then those putative solutions are no solutions to skepticism at all. They fail to exclude the form of skepticism that arises just in virtue of solipsism. And even if those proposed solutions do exclude solipsism, if we have not considered the question, it is not obvious that we would be justified in accepting these solutions. Moreover, these considerations suggest that skepticism about non-mental entities might require a different solution than skepticism of the kind that concerns mental entities.

Some proposed solutions to skepticism are such that their generalizability to knowledge of other minds is obvious; perhaps for these sorts of proposals, we needn't especially consider their extension to solipsism. Consider, for instance, approaches on which closure principles are altogether dispensed of. If these approaches succeed at all, they succeed for all forms of skepticism derived from closure principles, including solipsism-derived variants of skepticism. But for at least some other proposed solutions skepticism, it is at least not obvious whether they extend to knowledge of other minds. ${ }^{33}$ For instance, consider a certain kind of Moorean approach, on which Moorean facts are taken to be those whose plausibility is greater than any premise that might be adduced against it, and where this difference in plausibility is taken to be a merely predictive matter. ${ }^{34}$ Are facts such as others have thoughts and feelings, wishes and desires Moorean facts in this sense, 
much as other putative Moorean facts, such as there is a red square before me or I have hands? My suggestion is that we ought to ask the question. ${ }^{35}$

\section{EN D NOTES}

${ }^{1}$ Here and throughout, I employ 'sentient' in a broad way to mean, very roughly, psychology-having.

2 In the literature, 'solipsism' is sometimes used to pick out the weaker view that we do not know that others are conscious, even if they have psychologies (Borge 1999) or the stronger view that the only thing in the universe is your own mind (Schwitzgebel and Moore 2015).

${ }^{3}$ In a recent overview, Hyslop (2017) calls discussion of the view "nowadays unfashionable." Scholars who have bucked this trend by taking solipsism seriously include Avramides (2001), Gomes (2009, 2011, forthcoming), and Hyslop (1995). Note that the epistemological question of whether we enjoy knowledge of other minds is distinct from the question in philosophy of mind of how, given that we have knowledge of other minds, we come to obtain it. See Pickard (2003) for an explicit attempt to link the questions and see Overgaard (2012) for an illuminating defense of the claim, commonly made in the phenomenological tradition, that perception of other minds can help solve the skeptical problem of other minds.

${ }^{4}$ Chalmers declares the abductive solution "as good a solution to the problem of other minds as we are going to get" (1996: 246).

${ }^{5}$ Steup and Neta (2020). For a helpful overview, see Greco (2007).

${ }^{6}$ I thank Genia Schönbaumsfeld and Annalisa Coliva for pressing me on this point.

${ }^{7}$ See Smith (2010) and Gomes (2009) and Gomes (2011, forthcoming) for other routes of arguing for solipsism.

${ }^{8}$ Depending on how these 'others' are implemented, they might amount to full-scale hallucinations.

${ }^{9}$ For discussion, see Chalmers (1996, 2003a), Lyons (2009: ch. 4), and Smithies (2012).

${ }^{10}$ For a classic exchange, see Hawthorne (2005) and Dretske (2005).

${ }^{11}$ DeRose (1995).

${ }^{12}$ Turing (1956).

${ }^{13}$ I thank an audience member at the Eastern APA Society for Skeptical Studies for pressing me on this point.

${ }^{14}$ Block (1981).

${ }^{15}$ A related view closely related to behaviorism is interpretationism, of the kind associated with Dennett and Davidson. On one version of this view, some entity is sentient just in case that entity is such that a relevant interpreter does or could interpret them as rational. This view inherits all of the problems of behaviorism, in addition to generating some of its own. For, the view is susceptible to Turing machine-style counter-examples. The view also forces us to reject the possibility that someone might be sentient and deeply uninterpretable.

16 The simulation hypothesis has been subsequently explored or defended by multiple philosophers and physicists, including Arvan (2014, 2015), Beane et al. (2012), Campbell et al. (2017), Dainton (2002, 2012), Johnson (2011), and Mizrahi (2017).

${ }^{17}$ Barry Dainton suggests something along these lines $(2002,2012)$

18 There are, of course, many other strategies of defusing solipsism. One approach I don't mention here appeals to the claim that perception provides basic knowledge that others have minds. One worry about this approach is that perceptual knowledge of other minds is not obviously safe, in the sense that our perceptual system routinely and systematically gives 'false positives' concerning the animacy of others (Helton 2018: 243-4). While many have criticized safety as a necessary condition on knowledge (including myself, see Helton and Nanay 2019), I take it that safety is a good if defeasible proxy for whether some method is knowledge-producing.

${ }^{19}$ On some views, pieces of knowledge will be infinite. Thanks to Harvey Lederman for discussion on this point.

20 Those who take the recent envatment scenario to be a skeptical scenario include: Smith (1984:117), Glymour (1982: 173-5), Farrell (1986: 150), Tymoczko (1989: 294-5), Wright (1992: 86-90), Christensen (1993: 314-5), Forbes (1995: 207), and Brueckner (1999: 237).

${ }^{21}$ Strictly speaking, these considerations alone don't suggest that this knowledge must cross domains, but I'm presuming this 'domains' requirement to be an independently attractive constraint on external world skepticism.

22 I borrow the terminology from Friedman (2018), who considers junk beliefs in a different context, that of assessing Harman's (1986) suggestion one ought not clutter one's mind with such beliefs.

${ }^{23}$ I thank Liam Kofi Bright and Sarah McGrath for discussion on this point. 
24 My argument does not draw on generic beliefs, where generics are claims of the form Fs are a, since generics might turn out to be true even where very few or perhaps none of the relevant Fs are a. See, e.g., Leslie (2007, 2008, 2017).

25 This argument originates in Helton (2018: 249-51).

${ }^{26}$ See Helton (2018) for the argument that you literally visually perceive him as chasing the bus, which might help explain why correlative beliefs are difficult to resist.

27 If names rigidly designate individuals across worlds, without constraints on the kinds of individuals they can pick out, then beliefs about the mere existence of certain named social entities, such as Botswana exists, will turn out to be true in the solipsistic world. Even so, Botswana is a country might turn out to be false.

${ }^{28}$ For recent overviews, see Epstein (2019), Mason (2016) and Mason and Ritchie (forthcoming). I thank Robin Dembroff for discussion on this point.

${ }^{29}$ In the 'lonely being' scenario, you are sentient, so your consent, recognition, or other relevant attitudes might help ground some social entities. However, I'm presuming that, for at least many social entities, you lack the relevant social standing to play this role. E.g., suppose that being a member of the United Nations requires recognition by other members of the United Nations. Supposing you aren't a U.N. member, you cannot play this role, your being the only sentient creature in the universe notwithstanding.

${ }^{30}$ It is no part of my argument to claim that the kinds of knowledge I've discussed exhaust forms compromised by solipsism. Other possible candidates include knowledge about natural kinds and artifacts-should such kinds turn out to be mind-dependent (see, e.g., Khalidi 2013, Franklin-Hall 2015 and Thomasson 2003), testimonial knowledge - should such knowledge require others' intentions-and even, perhaps, moral and aesthetic knowledge-insofar as these require the attitudes of a collective of agents in the actual world.

31 I thank Tom Kelly and Harvey Lederman for pressing me on this point.

32 A different kind of critic might suggest that the considerations I have adduced support the view that we should suspend judgment on the question of whether solipsism is a form of skepticism. I lack the space to consider this agnostic response here, but I will merely note: The morals I draw out for epistemology obtain even on the view that we should suspend judgment on the question of whether, for creatures like ourselves, solipsism is a form of skepticism.

33 In a companion piece (Helton unpublished), I argue from some of the same considerations presented here that Chalmers' (2003b, forthcoming) proposed structuralist approach to skepticism falls prey to the problem that it does not succeed when it comes to social beliefs, even if it succeeds when it comes to non-social beliefs. My criticism of Chalmers does not derive from the claim that solipsism is a form of skepticism. So, one might accept my criticism of Chalmers' approach, whilst denying that solipsism is a form of skepticism. Conversely, one might accept the claim I defend here that solipsism is a form of skepticism, whilst denying that structuralism falls to my complaint.

34 This interpretation of Mooreanism is offered and rejected in Kelly (2005, see esp. 182-185).

35 For helpful feedback on this paper and related work, I would like to thank audience members at: the New Directions in Mind Seminar as Cambridge University, an APA Eastern Session on the Society for Skeptical Studies, the CUNY Graduate Center, the Desert Philosophy Workshop, The Ohio State University, the MAP/ELLMM working group at Yale University, the Minds, Selves, and Technology Conference at the University of Lisbon, the Theoretical Philosophy Workshop at the University of Chicago, and multiple audiences at Princeton University. Special thanks to: Josh Armstrong, Katalin Balog, Liam Kofi Bright, Simon Cabulea May, Ben Callard, Annalisa Coliva, Tim Crane, Lindsay Crawford, Kevin Davey, Heather Demarest, Louise Daoust, Carolyn Dicey Jennings, Adam Elga, Johann Frick, Nemira Gasiunas, Jeff Helmreich, Mark Johnston, Tom Kelly, Harvey Lederman, Sarah McGrath, Eliot Michaelson, Shyam Nair, Nico Orlandi, Tom Pashby, David Plunkett, Adriana Renero, Amy Sepinwall, James Shaw, Patrick Todd, Genia Schönbaumsfeld, and Will Starr.

\section{REF E R EN C ES}

Arvan, M. (2014, December). A Unified Explanation of Quantum Phenomena? The Case for the Peer-to-Peer Simulation Hypothesis as an Interdisciplinary Research Program. The Philosophical Forum, 45(4), 433-446.

Arvan, M. (2015). The Peer-to-Peer Simulation Hypothesis and a New Theory of Free Will. Scientia Salon. https://scientiasalon.wordpress.com/2015/01/30/the-peer-to-peer-hypothesis-and-a-new-theory-of-freewill-a-brief-overview/? Access October 8, 2021. 
Avramides, A., 2001, Other Minds, London: Routledge.

Beane, S. R., Davoudi, Z., \& Savage, M. J. (2012). Constraints on the Universe as a Numerical Simulation. arXiv preprint arXiv:1210.1847.

Block, N. (1981). Psychologism and behaviorism. The Philosophical Review, 90(1), 5-43.

Borge, S. (1999). All you zombies. David Chalmers' Metaphysical Solipsism In Uwe Meixner Peter Simons (ed.), Metaphysics in the Post-Metaphysical Age. Austrian Ludwig Wittgenstein Society.

Bostrom, N. (2003). Are we living in a computer simulation? The Philosophical Quarterly, 53(211), 243-255.

Brueckner, A. (1999). Transcendental Arguments from Content Externalism. In R. Stern (ed.), Transcendental Arguments: Problems and Prospects. Oxford: Clarendon Press.

Campbell, T., Owhadi, H., Sauvageau, J. \& Watkinson, D. (2017). On Testing the Simulation Theory. International Journal of Quantum Foundations 3: 78-99.

Chalmers, David. (1996). The Conscious Mind: In Search of a Fundamental Theory. New York: Oxford University Press.

Chalmers, David. (2003a). The Content and Epistemology of Phenomenal Belief. In Conscious ness: New Philosophical Perspectives, edited by Q. Smith and A. Jokic. New York: Oxford University Press.

Chalmers, D. (2003b). The Matrix as metaphysics. Science Fiction and Philosophy From Time Travel to Superintelligence, 36.

Chalmers, D. J. (2018). Structuralism as a Response to Skepticism. The Journal of Philosophy, 115(12), 625-660.

Chalmers, D. (forthcoming). Reality +: Virtual Worlds and the Problems of Philosophy.

Christensen, D. (1993). Skeptical Problems, Semantical Solutions. Philosophy and Phenomenological Research 53 (2): 301-21.

Dainton, B. (2002). Innocence lost simulation scenarios: Prospects and consequences. Retrieved March 31, 2021 from http://www.simulation-argument.com

Dainton, B. (2012). On singularities and simulations. Journal of Consciousness Studies, 19(1-2), 42-85.

DeRose, K. (1995). Solving the skeptical problem. The philosophical review, 104(1), 1-52.

Dogramaci, S. (2020). Does my total evidence support that I'm a Boltzmann Brain? Philosophical Studies, 177(12), 3717-3723.

Dretske, F. (2005). Reply to hawthorne. Contemporary debates in epistemology, 43-46.

Epstein, B. (2019). "Social Ontology”, The Stanford Encyclopedia of Philosophy (Winter 2019 Edition), Edward N. Zalta (ed.), URL = https://plato.stanford.edu/archives/win2019/entries/social-ontology/.

Farrell, F. (1986) Putnam and the Vat-People. Philosophia 16 (2): pp. 147-60.

Forbes, G. (1995). Realism and Skepticism: Brains in a Vat Revisited. The Journal of Philosophy 92 (4): pp. 205-22.

Franklin-Hall, L. R. (2015). Natural kinds as categorical bottlenecks. Philosophical Studies, 172(4), 925-948.

Friedman, J. (2018). Junk beliefs and interest-driven epistemology. Philosophy and Phenomenological Research, 97(3), 568-583.

Gomes, A., (2009). Other Minds and Perceived Identity, Dialectica, 63: 219-230.

Gomes, A. (2011). Is There a Problem of Other Minds? Proceedings of the Aristotelian Society, 111: 353-373

Gomes, A. (forthcoming). Scepticism about Other Minds. In D. Machuca \& B. Reed (eds.) Skepticism: From Antiquity to Present.

Greco, J. (2007). External world skepticism. Philosophy Compass, 2(4), 625-649.

Glymour, C. (1982) Conceptual Scheming or Confessions of a Metaphysical Realist. Synthese 51 (2): pp. 169-80.

Harman, G. (1986). Change in view: Principles of reasoning. Cambridge, MA: MIT Press.

Hawthorne, J. (2005). The case for closure. Contemporary debates in epistemology, 26-43.

Helton, G. (unpublished manuscript). On Being a Lonely Brain-in-a-Vat: Structuralism, Solipsism, and the Threat of External World Skepticism.

Helton, G. (2018). Visually perceiving the intentions of others. The Philosophical Quarterly, 68(271), 243-264.

Helton, G. \& Nanay, B. (2019). Amodal completion and knowledge. Analysis, 79(3), 415-423.

Hyslop, A. (1995). Other Minds, Dordrecht: Kluwer.

Hyslop, A. (2017). “Other Minds”, The Stanford Encyclopedia of Philosophy (Summer 2017 Edition), Edward N. Zalta (ed.), URL = https://plato.stanford.edu/archives/sum2017/entries/other-minds/.

Johnson, D. K. (2011). Natural Evil and the Simulation Hypothesis. Philo 14 (2):161-175.

Kelly, T. (2005). Moorean facts and belief revision, or can the skeptic win? Philosophical perspectives, 19, 179-209.

Khalidi, M.A. (2013). Natural Categories and Human Kinds, Cambridge: Cambridge University Press. 
Leslie, S. (2007). Generics and the structure of the mind. Philosophical Perspectives, 21(1), 375-403.

Leslie, S. (2008). Generics: cognition and acquisition. Philosophical Review, 117(1), 1-47.

Leslie, S. (2017). The original sin of cognition: Fear, prejudice, and generalization. The Journal of Philosophy, 114(8), 393-421.

Lyons, J.C. (2009). Perception and basic beliefs: Zombies, modules and the problem of the external world. OUP USA. Mason, R. (2016). The metaphysics of social kinds. Philosophy Compass, 11(12), 841-850.

Mason, R. \& Ritchie, K. (forthcoming). Social Ontology. In Ricki Bliss \& James Miller (eds.), Routledge Handbook of Metametaphysics. PhilArchive copy v1: https://philarchive.org/archive/MASSO-3v1

Mizrahi, M. (2017). The Fine-Tuning Argument and the Simulation Hypothesis. Think 16 (47):93-102.

Overgaard, S. (2012). Other people. The Oxford handbook of contemporary phenomenology, 460-79.

Pickard, H. (2003). Emotions and the problem of other minds. Royal Institute of Philosophy Supplement, 87-104.

Schwitzgebel, E., \& Moore, A. T. (2015). Experimental evidence for the existence of an external world. Journal of the American Philosophical Association, 1(3), 564-582.

Smith, J. (2010). The conceptual problem of other bodies. Proceedings of the Aristotelian Society 110: $201-217$.

Smith, P. (1984). Could we be Brains in a Vat? Canadian Journal of Philosophy 14 (1): pp. 115-23.

Steup, M. and Neta, R. (2020). "Epistemology”, The Stanford Encyclopedia of Philosophy (Fall 2020 Edition), Edward N. Zalta (ed.), URL = https://plato.stanford.edu/archives/fall2020/entries/epistemology/

Smithies, D. (2012). The mental lives of zombies. Philosophical Perspectives, 26, 343-372.

Thomasson, A. L. (2003). Foundations for a social ontology. ProtoSociology, 18, 269-290.

Turing, A. M. (1956). Can a machine think. The world of mathematics, 4, 2099-2123.

Tymoczko, T. (1989). In Defense of Putnam's Brains. Philosophical Studies 57 (3): pp. 281-97.

Wright, C. (1992). On Putnam's Proof that We are not Brains-in-a-Vat. Proceedings of the Aristotelian Society 92 (1): pp. 67-94.

How to cite this article: Helton G. Epistemological solipsism as a route to external world skepticism. Philosophical Perspectives. 2021;1-22. https://doi.org/10.1111/phpe.12146 